\title{
Correction to: Morphology of the feeding apparatus in the herbivorous mudskipper, Boleophthalmus pectinirostris (Linnaeus, 1758)
}

\author{
Loi X. $\operatorname{Tran}^{1}{ }^{10} \cdot$ Yu Maekawa ${ }^{2} \cdot$ Kiyoshi Soyano ${ }^{1,3} \cdot$ Atsushi Ishimatsu $^{1,3}$ (])
}

Published online: 28 March 2020

c) Springer-Verlag GmbH Germany, part of Springer Nature 2020

\section{Correction to: Zoomorphology}

https://doi.org/10.1007/s00435-020-00476-3

Authors would like to correct the errors in the discussion, under "Functional morphology of the feeding apparatus in Boleophthalmus pectinirostris" part.

The sentence "The average space between the gill rakers on the posterior three rows $(56.6 \pm 3.8 \mu \mathrm{m})$ is far smaller than the size of six dominant diatom species recovered from the alimentary tract of B. pectinirostris (Gyrosigma gibbyi, G. sp., G. wansbeckii, Nitzschia amphibia, N. gyrosigma, and Pleurosigma sterrenburgii), whose longer axis length ranges from $189.7 \pm 26.2$ to $1396.4 \pm 408.7 \mu \mathrm{m}(N=5)$, and whose shorter axis length (SAL) ranges from $65.3 \pm 11.2$ to 187.2 $\pm 14.1 \mu \mathrm{m}$, except for Nitzschia amphibia (SAL $37.0 \pm$ $10.7 \mu \mathrm{m}$ ) and Gyrosigma wansbeckii (SAL $51.0 \pm 14.7 \mu \mathrm{m}$, $N=5$, Tran et al., unpublished data)" should be corrected to "The average space between the gill rakers on the posterior three rows $(56.6 \pm 3.8 \mu \mathrm{m})$ is far smaller than the size of six dominant diatom species recovered from the alimentary tract of B. pectinirostris (Gyrosigma cf. gibbyi, G. cf. wansbeckii, G. fasciola var. fasciola, Navicula sp., Nitzschia sp., and Pleurosigma sterrenburgii), whose longer axis length ranges from $189.7 \pm 26.2$ to $1396.4 \pm 408.7 \mu \mathrm{m}(N=5)$, and whose

The original article can be found online at https://doi.org/10.1007/ s00435-020-00476-3.

Loi X. Tran

txloi@ctu.edu.vn

1 Graduate School of Fisheries and Environmental Sciences, Nagasaki University, 1-14 Bunkyo-machi, Nagasaki 852-8521, Japan

2 The University Museum, The University of Tokyo, 7-3-1 Hongo, Bunkyo-ku, Tokyo 113-0033, Japan

3 Institute for East China Sea Research, Organization for Marine Science and Technology, Nagasaki University, 1551-7 Tairamachi, Nagasaki 851-2213, Japan shorter axis length (SAL) ranges from $65.3 \pm 11.2$ to 187.2 $\pm 14.1 \mu \mathrm{m}$, except for Navicula sp. (SAL $37.0 \pm 10.7 \mu \mathrm{m}$ ) and Gyrosigma cf. wansbeckii (SAL 51.0 $\pm 14.7 \mu \mathrm{m}, N=5$, Tran et al., unpublished data)".

Publisher's Note Springer Nature remains neutral with regard to jurisdictional claims in published maps and institutional affiliations. 